\title{
AN INDUSTRY SURVEY ON THE USE OF GRAPHENE- REINFORCED CONCRETE FOR SELF-SENSING APPLICATIONS
}

\author{
I.Papanikolaou ${ }^{1 *}, 2$, A.Al-Tabbaa ${ }^{1}$ and M.Goisis ${ }^{3}$ \\ ${ }^{I}$ Department of Engineering, University of Cambridge, Cambridge, United Kingdom \\ ${ }^{2}$ Costain Group Plc., Maidenhead, United Kingdom \\ ${ }^{3}$ Italcementi Heidelberg Cement Group, Bergamo, Italy \\ * Corresponding author
}

\begin{abstract}
Concrete is the most widely used construction material in infrastructure. However, concrete structures often suffer from poor durability performance that necessitate an extensive inspection and maintenance regime. Hence, there is an impending need for reducing inspections and repairs of concrete structures by developing materials that look after themselves, i.e. have biomimetic attributes. One such example is the development of self-sensing (or self-monitoring) concrete; a material with the ability to sense the presence of stresses, cracks and damage on its structure. Such a material would reduce the need for unnecessary inspections of structures that are not only costly but often very disruptive for the public. This paper provides a critical review of cutting-edge research in self-sensing concrete and focuses on graphene nanoplatelets (GNPs) - an emerging nanomaterial that is reported to have a positive effect on the mechanical, durability, and sensing properties of cement composites. The insight gained from an industry survey on the use of graphene for self-sensing concrete is presented and is structured around the identified commercial, sustainability and technical opportunities and barriers. It is found that improvement in tensile/flexural strength and the development of a self-sensing mechanism are the main opportunities, whilst the upfront cost of the material is cited as the main barrier. This paper provides a targeted study of applying graphene-reinforced cement composites for self-sensing applications and will act as a reference point for future exploitation of this emerging material.
\end{abstract}

\section{Introduction}

Concrete is the most widely used construction material for infrastructure projects such as tunnels and bridges. In the UK, the infrastructure pipeline from 2016-2021 accounts for more than $£ 400$ billion (HM Infrastructure and Projects Authority, 2016), hence demand for concrete is expected to remain very high. Concrete structures exhibit good mechanical properties and durability if designed and constructed correctly. However, many structures are subject to frequent repair and maintenance (R\&M), which is expensive and leads to a great environmental cost and disruption for the public (Gardner et al., 2018), (AlTabbaa and Paine, 2018). From 2011 to 2015, approximately a fifth of the total civil engineering construction output in the UK was due to R\&M works (HM Treasury, 2010).

Structural health monitoring (SHM) has been used over the recent years to assess structural condition and damage. SHM involves the integration of sensors, data transmission and processing that allow an informed decision making process about the condition of structures (Xu, 2012). However, the use of external sensors has often resulted in high costs, low sensitivity, incompatibility with structural materials and poor durability (Horszczaruk, Sikora and Lukowski, 2016), (Spencer, 2009). Moreover, in the UK, asset owners use visual inspections as the primary source of data for their asset condition (Bennetts et al., 2016), which not only leads to network disruption whilst carrying out the inspections, but also increases the health and safety risk and cost. Therefore, there is an impending need to reduce inspections and repairs of concrete structures and to also minimise the dependence on external sensors. This can be achieved by developing materials that look after themselves, i.e. have biomimetic attributes. Biomimetic materials refer to those that mimic nature, they can sense and respond to their environmental conditions, selfimmunise and protect themselves and heal if they are damaged (Al-Tabbaa et al., 2017), (Van Tittelboom and De Belie, 2013).

Over the last decades, research has focused on the development of nanomaterials; which refers to materials that are less than 100 nanometers in one of their dimensions. The emergence of nanomaterials provides great opportunities for reinforcing the cement matrix at nanoscale (Paul et al., 2018), (Zhu, Bartos and Porro, 2004), (Norhasri, Hamidah and Fadzil, 2017) and they could also be used to instigate a self-sensing mechanism. One such promising nanomaterial is graphene, a 2-dimensional structure that comprises of a single layer of carbon atoms arranged in a hexagonal lattice (Geim and Novoselov, 2007). Graphene was isolated in 2004 by Geim and Novoselov through exfoliation of graphite and therefore stacked graphene layers will result in graphite (Madhuri and Maheshwar, 2015). Graphene's properties include a very high intrinsic strength (130 GPa), a Young's modulus of $1 \mathrm{TPa}$, very high thermal and electrical conductivity, as well as complete impermeability to any gases (Novoselov et al., 2012). Due to their unique properties, graphene nanomaterials are a promising candidate 
for reinforcing concrete at nano-level and for initiating advanced functionalities, such as self-diagnosing. Therefore, the motivation for this research is to explore the potential of using graphene nanomaterials in concrete by not only considering the technical merits but also by investigating the commercial, safety and environmental aspects.

\section{Self-sensing concrete}

Self-sensing or monitoring concrete refers to a structural material that can monitor its own condition and identify if there is any damage without any external intervention in the form of embedded, attached or remote sensors (Han, Ding and $\mathrm{Yu}$, 2015). The benefit of using such a material is twofold; firstly, structural performance is maintained or even enhanced and secondly, the sensing performance is superior to external sensors due to the intrinsic property, the higher sensitivity, natural compatibility and extended durability of the sensing component. It is also important to highlight that self-sensing materials are themselves structural materials hence they would not compromise the overall structural performance (Chung, 1998). This section focuses on the sensing types and composition of self-sensing concrete.

\subsection{Sensing types}

Strain sensing is the most common property explored. Piezoresistive effect is the underlying principle for the function of sensing materials. Piezoresistivity refers to the change in electrical resistivity of a material with strain and can be measured using the electrical resistance (with DC or AC) to monitor the strain of a material (Chung, 2002). The sensing of irreversible strain is what allows damage sensing, whilst the sensing of reversible strain allows dynamic load monitoring (Chen and Chung, 1996).

Damage sensing is based on the hypothesis that damage causes some breakage of the conductive network, therefore resulting in an irreversible increase in the electrical resistance (Han, Yu and $\mathrm{Ou}, 2014)$. Spatially resolved sensing of both strain and damage has also been achieved by using an array of electrical contacts, with the outermost contacts for passing current and the remaining contacts used in pairs for measuring the voltage (Chung, 2012). Temperature sensing has also been developed (Chung, 2012) with carbon and steel fibres.

\subsection{Functional fillers}

A conventional concrete matrix has no or poor sensing capability and it acts as an electrical insulator (Neville, 2011), (Al-Dahawi et al., 2017). Hence, conductive, functional fillers need to be incorporated in order to reduce the electrical resistance of the cement composite and aid the monitoring of piezoresistive effects and damage (Han, $\mathrm{Yu}$ and $\mathrm{Ou}, 2014)$. To date, there are at least 10 different types of functional fillers along with hybrid combinations that have been explored for self-sensing properties, including natural graphite, carbon nanotubes and fibers, carbon black and the nanomaterial of graphene (Han, Ding and $\mathrm{Yu}, 2015)$, (Chung, 2012), (AlDahawi et al., 2017). The choice of the functional filler is important as it will dictate the resulting mechanical, durability and electrical properties of the material. The fillers can be categorised both in terms of the size and shape and a simplified summary is shown in Figure 1. Finally, the concentration of the functional filler is of utmost importance. The minimum dosage required to create conductive networks within the cement matrix is known as the percolation threshold. This percolation threshold will vary between functional fillers and their concentration will also affect the mechanical and durability properties. As an example, a carbon black content of approximately $1.34 \%$ by volume was found to be the percolation threshold for cement composites but at that content the compressive strength is less than the control mix and it decreases further with increasing carbon black content (Dai et al., 2010). Therefore, finding the right balance between structural performance and electrical conductivity is necessary for the success of functional fillers.

Figure 1: Simplified summary of the functional fillers
for self-sensing applications
\begin{tabular}{|l||l|}
\hline Fibre shape & Particle (spherical) shape \\
\hline $\begin{array}{l}\text { Macroscale } \\
\text { Steel fiber }\end{array}$ & Steel slag \\
\hline \hline $\begin{array}{l}\text { Microscale } \\
\text { Carbon fiber }\end{array}$ & $\begin{array}{l}\text { Graphite powder } \\
\text { Nickel powder }\end{array}$ \\
\hline \hline $\begin{array}{l}\text { Nanoscale } \\
\text { Carbon nanofiber } \\
\text { Carbon nanotube }\end{array}$ & $\begin{array}{l}\text { Carbon black } \\
\text { Graphene oxide (GO) } \\
\text { Graphite nanoplatelets (GNPs) }\end{array}$ \\
\hline
\end{tabular}

\section{Graphene-cement composites}

A graphene/cement composite is an emerging advanced material that could be optimised in several construction applications. Graphene comes in different forms - the most commonly researched types for cement composites are Graphene Oxide (GO) and Graphene/Graphite Nanoplatelets (GNPs). GO is a graphene derivative with various oxygencontaining functional groups on its surface which render the GO sheet hydrophilic and facilitate its dispersion in water $(\mathrm{Xu}$ et al., 2018). GNPs is a sheet-like material that consists of a small number of well-defined graphene layers (typically less than 100 layers and a thickness of less than $100 \mathrm{~nm}$ ) (Shamsaei et al., 2018). The key difference between GO and GNPs from a concrete perspective, lies in the dispersibility potential and the effect on electrical properties. GO is easier to disperse in water due to the oxygen groups that are present whilst GNPs do not possess any oxygen groups. However, due to the oxygen groups, GO acts as an electrical insulator and does not allow for advanced functionalities such as self-sensing to be developed (Zheng et al., 2017). This paper therefore focuses on GNPs that not only are reported to improve the strength and durability, but to also allow for improved conductivity and hence a self-sensing mechanism. 


\subsection{GNPs dispersion}

GNPs possess strong, attractive forces and are also hydrophobic which makes their dispersion in water and in aqueous alkaline environment critical. Dispersion of graphene materials is facilitated both by mechanical and chemical methods. The mechanical methods include high speed shear mixing, magnetic stirring and ultrasonication. The chemical methods use surfactants or surface modification aids. Surfactants help dispersion of graphene nanomaterials by wetting, electrostatic repulsion and/or steric hindrance actions, whilst mineral admixtures work by gradation, adsorption and separation effects (Han, Ding and Yu, 2015).

Polycarboxylate comb-polymers (PCE), used as superplasticisers in concrete technology, have been tested with positive results to enable the dispersion of graphene in cementitious mixtures. Zhao et al. (2018) found that PCE have superior performance compared to other types when dispersing graphene oxide. This is in agreement with (Papanikolaou, Litina and Al-tabbaa, 2018) who showed that a PCE from BASF, MasterGlenium C315, was more efficient in dispersing GNPs that other types as confirmed by zeta-potential measurements, rheology and UV-Visible spectroscopy. Sonication (Figure 2) has also been found to be an effective process to disperse graphene oxide and carbon nanotubes (Sobolkina et al., 2012; Chuah et al., 2018)). The mixing sequence can also be critical and better results have been obtained when adding the nanomaterial to water and superplasticiser first and then adding the liquid to the cementitious mixture (Lu et al., 2017).

Figure 2: Aqueous dispersion of GNPs (the product is G2NanPaste supplied by Nanesa) before (left) and after 2 hours of sonication (right), in the presence of PCE.

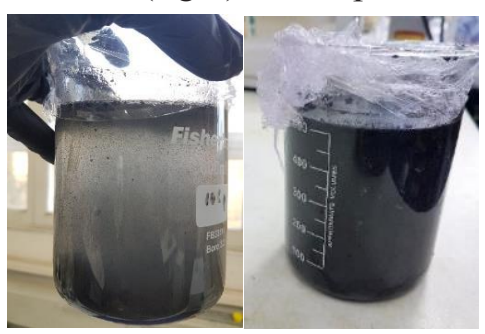

The GNP contents may vary from $0.02 \%$ to $3 \%$ by weight of cement (bwoc) but more often dosages in the range of 0.02 $1.0 \%$ bwoc are encountered for paste and mortar mixtures. Depending on the graphene type, dispersion process, mixture composition and targeted properties, the optimal content may vary and targeted experiments are required to determine it. Overall, dispersion remains a key challenge and extensive experiments are needed to fully realise the potential of graphene in cement composites.

\subsection{GNPs effect on concrete properties}

The effects of adding GNPs in cement composites have been investigated by many researchers. Overall, there is an agreement as to which performance aspects can be improved with GNPs addition. However, as mentioned earlier, differences in dispersion techniques, type of graphene and dosage influence the results reported in the literature and make the comparison between them very difficult. Table 1 provides a simplified summary of what is shown in the literature, followed by a short review of the effects of GNPs on the various properties of concrete.

Table 1: Simplified summary of the frequent effect of GNPs on some properties of the cement mixtures

\begin{tabular}{|l|l|}
\hline Property & GNPs \\
\hline Electrical conductivity & Increase \\
\hline Fluidity/workability & Decrease \\
\hline Setting times & No information \\
\hline Rate of hydration & Minimal effect \\
\hline Porosity & Decrease \\
\hline Compressive strength & Increase \\
\hline $\begin{array}{l}\text { Tensile \& flexural } \\
\text { strength }\end{array}$ & Increase \\
\hline Crack propagation arrest & Increase \\
\hline Chloride attack resistance & Increase \\
\hline Water penetration depth & $\begin{array}{l}\text { Decrease but } \\
\text { dependent on porosity }\end{array}$ \\
\hline
\end{tabular}

Research has been undertaken on the effect of GNPs on the electrical properties of cement composites. This is the application where GNPs show their superior performance due to the outstanding electrical conductivity of the basic lattice. Bai et al. (2018) tested, with a four-probe measurement, the effect of few-layer GNPs on the electrical conductivity of cement composites under different test parameters. The results showed that a percolation phenomenon (rapid decrease in resistivity after a certain conductive filler content) exists between $0.8 \%$ and $1.2 \%$ GNPs content by mass of cement with conductivity increasing by 3 orders of magnitude at $1.2 \%$ content. Other authors have also investigated the electrical conductivity and the resultant piezoresistive properties of GNPs-reinforced cement mixtures. A minimum GNPs content of 2.4 vol.\% was required to achieve almost linear piezoresistive characteristics when the GNPs-modified cement mortar was subject to cyclic tensile strain (Pang et al., 2014). In another study, a percolation threshold at GNPs content of $2 \%$ by volume of the mixture was found and in the percolation zone there was a sensitive piezoresistive effect and stable response to cyclic quasi static and dynamic loading conditions (Sun et al., 2017).

In terms of traditional basic rheological properties, when nanomaterials are added in the cement matrix, usually a 
reduction of the workability of the mixture is shown. For GNPs, this is mainly due to the large specific surface area that requires more water to wet the surfaces and consequently leads to a decrease of the free water in the mixture (Wang, Jiang and $\mathrm{Wu}, 2016)$ with a consequent increase in inter-particle friction (Chuah et al., 2014). Information on setting times is lacking, whilst there are discrepancies about the effect of GNPs on the rate of hydration.

Tong et al. (2016) showed with AFM scans that the GNPs can substantially reshape the microstructure of the cement paste and that an interfacial bond is developed between the C-S-H gel and the GNPs. However, very limited studies have been undertaken on the effect of GNPs on the microstructure of the cement composites and their effect on the hydration products, so this is an area where further research is needed. Several authors have confirmed the reduction in porosity with GNP addition, mainly using Mercury Intrusion Porosimetry (MIP), and a shift from larger to finer pores has also been observed (Du and Pang, 2015), (Wang and Zhao, 2017), (Wang, Zhao and Zhang, 2018).

As expected, the reduction in porosity is beneficial for the mechanical and durability performance. A summary of the reported compressive strength results is illustrated in Figure 3. Most authors found an improvement in compressive strength when GNPs are added from $0.01 \%-1 \%$ dosage by weight of cement. However, the properties of the GNPs that are used, the dispersion techniques and the cement type vary between the authors and this explains why there is no agreement in percentage improvement of compressive strength. The trend is similar for tensile/flexural strength, with most authors reporting an increase in strength with GNPs addition. Nanoindentation testing also showed that the hardness of the cement matrix can improve with GNPs (Han et al., 2017).

Figure 3: Summary of the literature on effect of GNPs on compressive strength of an ordinary Portland Cement composite at 28 days

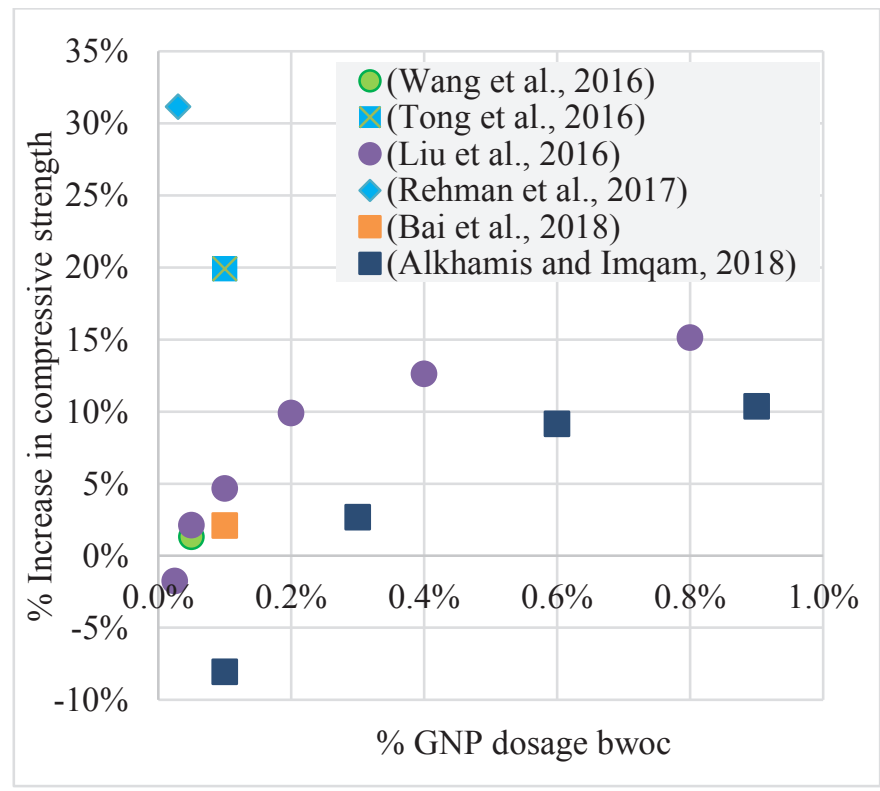

The effect of graphene on the durability of cement composites has been investigated primarily through rapid chloride penetration testing and water permeability. It has been found that GNPs improve the durability performance, mainly due to a reduction in porosity. The water penetration depth has been found to decrease with an increasing GNPs content (Dimov et al., 2018) and this is also the case for the chloride penetration depth (Du, Gao and Pang, 2016). However, similarly to GO (Xu et al., 2018), the durability of GNPs-reinforced cement composites has not been widely investigated and more research is needed in this area.

\section{Industry survey}

An industry survey was undertaken in order to understand the main problems encountered with the repair of concrete structures, the use of sensors technology and to also identify the key opportunities and blockers for using graphene in cement composites. The main objectives of this market survey were to identify:

(a) the most common performance issues with concrete structures, their severity, timescales for repair and their consequential effects;

(b) the use of external sensors for structural condition monitoring and the challenges encountered with the use of such sensors;

(c) the opportunities and barriers for graphene nanomaterials in cement composites for performance improvement.

The market survey was conducted online, using the survey tool "SurveyMonkey". Prior to distribution, a small number of volunteers trialled the survey to ensure that there were no problems. The survey was distributed via email to approximately 500 professionals working in the construction and materials sectors in the UK and abroad, who were chosen based on the authors' contacts. The survey comprised of given lists, 5-point Likert scales and free text questions. All questions were optional.

\subsection{Industry survey results}

There were 78 responses to the survey. Data on the respondents' background was asked at the end of the survey but is presented first here for context. As illustrated in Figure 4 , over half of the respondents come from a contracting background, whilst $22 \%$ come from a consulting background. Infrastructure clients and materials manufacturers (including chemical and cement companies) account for $10 \%$ each whilst $7 \%$ represent academia, trade bodies and technology vendors. Over half of the respondents have more than 15 years of professional experience $(55 \%)$ and $39 \%$ have $5-15$ years of experience so they are expected to be in mid-senior level. Many of these respondents are technical directors and chief engineers in their organisations, with $8 \%$ being at Fellow level, whilst $28 \%$ hold a $\mathrm{PhD}$ and/or are professionally qualified. From the 78 respondents, 61 operate in the UK $(78 \%)$ whilst the remaining operate in countries including mainland Europe 
(Germany, France, Italy), Australia, New Zealand and Hong Kong.

Figure 4: Survey respondents' background

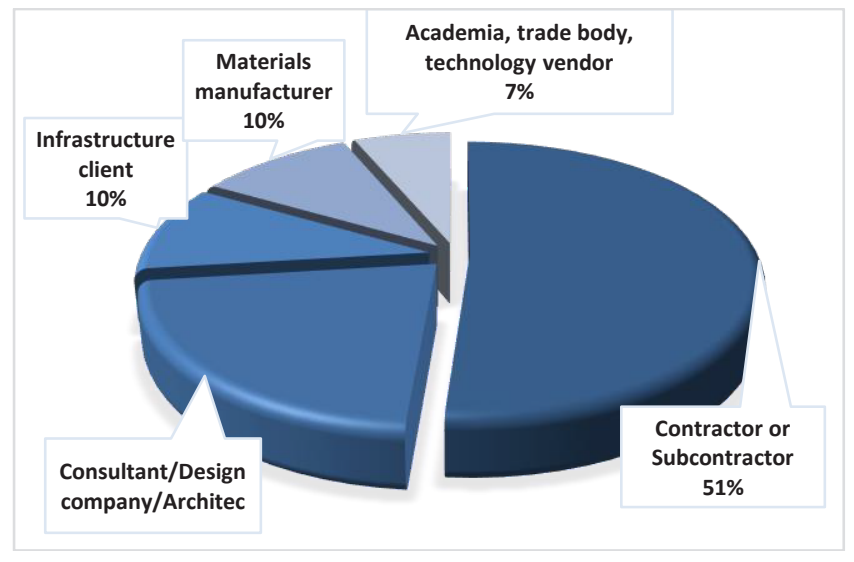

\subsection{Performance issues with concrete structures}

Firstly, the survey participants were asked to identify the most common performance issues that they have encountered with concrete structures (up to two choices) and the results are illustrated in Figure 5. Cracking due to poor workmanship was chosen by $48 \%$ of the respondents whilst cracking due to poor specification and material performance was chosen by $38 \%$. Other includes issues with design, insufficient performance in tension without reinforcement, chemical attack in tank bunds, chloride/carbonation attack in waste water treatment works and inadequate training of those placing the concrete or supervising the works. Next, the participants were asked to rate the concrete failures that they have encountered in the last three years from mild $(=1)$ to strong $(=5)$ and the average number was found to be 2.01 (76 responses). This indicates, that despite concrete failures occurring, they are often mild.

Figure 5: The most common performance issues encountered with concrete structures (according to participants, up to two choices allowed)

\begin{tabular}{|l|l|l|l|}
\hline \multicolumn{5}{c}{ \% Respondents } \\
Cracking due to poor workmanship \\
Cracking due to poor specification-... \\
Water ingress/penetration \\
Reinforcement corrosion \\
Chemical/environmental damage \\
Temperature gradients leading to... \\
Other (please specify) \\
Cracking due to overloading
\end{tabular}

Figure 6 shows that poor concrete performance results in immediate repair (selected by $66 \%$ of the respondents), followed by enhanced structural monitoring which was selected by $41 \%$. Other refers to programme delays and resequencing, which was named as a consequence of poor performance by 4 respondents. Finally, when concrete requires remedial work, over half of the respondents $(54.5 \%)$ said that repairs take place within 3 months, $29.9 \%$ said that it takes place within 3-12 months, whilst 15.6\% said that it takes longer than a year for the repair to take place.

Figure 6: The most common effects of poor concrete performance (according to participants, up to two choices allowed)

\begin{tabular}{|} 
Immediate repair \\
Enhanced monitoring of the structure \\
Company brand damage and lack of... \\
Change in the planned maintenance... \\
Other (please specify) \\
Effect on health, safety, environment
\end{tabular}

\subsection{Inspection and monitoring of concrete structures}

The second section of the survey focused on the use of sensors for structural health monitoring. When asked whether their company is involved with inspection and monitoring of concrete structures (such as sensor installation, carrying out and commissioning inspections etc.), $51.3 \%$ of the participants responded positively and $34.6 \%$ negatively. When asked whether they have a very negative $(=1)$ or very positive view $(=5)$ on external sensors for concrete structures, the average number chosen was 3.5, showing an inclination towards a positive view. Lastly, when asked about the common challenges encountered with external sensors, the cost of installation, data interpretation, lifetime and durability of the sensors were found to be the most frequent challenges encountered (Figure 7). 14\% of the respondents haven't encountered any challenges with external sensors, whilst in other, many respondents quoted the lack of client support for lifecycle management as a key challenge when using external sensors.

Figure 7: The most common challenges you have encountered with sensors (according to participants, up to two choices allowed)

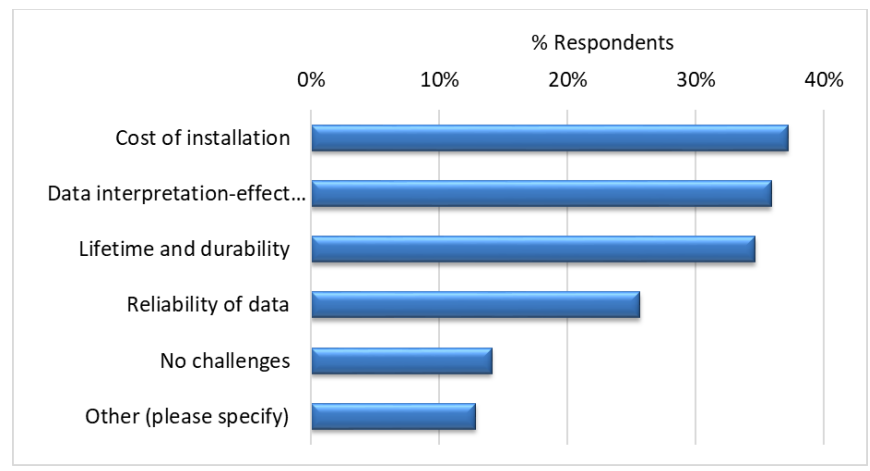




\subsection{Graphene-reinforced cement composites}

When asked about their familiarity with graphene materials, $37 \%$ of the respondents responded positively and 63\% negatively. This is a slight improvement compared to June-July 2017 , when a similar survey was run and only $32 \%$ of the respondents (34 in total) were familiar with graphene nanomaterials and their potential applications in construction (Papanikolaou, 2017). This is expected as research in this area is still very novel.

Next, the participants were asked to identify the main opportunities for graphene nanomaterials to improve concrete performance as well as the key barriers for introducing this novel material in construction. The results are tabulated in Figure 8 and Figure 9. Improvement in tensile and flexural strength was chosen by $41 \%$ of the respondents as the main priority area, closely followed by the potential for generating a self-sensing/self-diagnosing mechanism $(39.7 \%$ of the participants). Graphene nanomaterials could improve the tensile and flexural strength of concrete and replace traditional reinforcement to an extent. Advanced functionalities, such as self-sensing, should also be a priority target area for graphene nanomaterials. Durability performance, including an improvement in chloride attack resistance and a reduction in the water penetration depth, were found to be of less importance according to the respondents. This could be because over half come from a contracting organisation and not always deal with the long-term effects of poor concrete performance. Other refers to the overall reduction in concrete sections due to advanced performance that would also benefit the sustainability of the structures, as well as to an improvement in fresh properties and the thermal conductivity of the mix.

Figure 8: The priority areas for performance improvement when adding graphene nanomaterials in concrete (according to participants, up to two choices allowed)

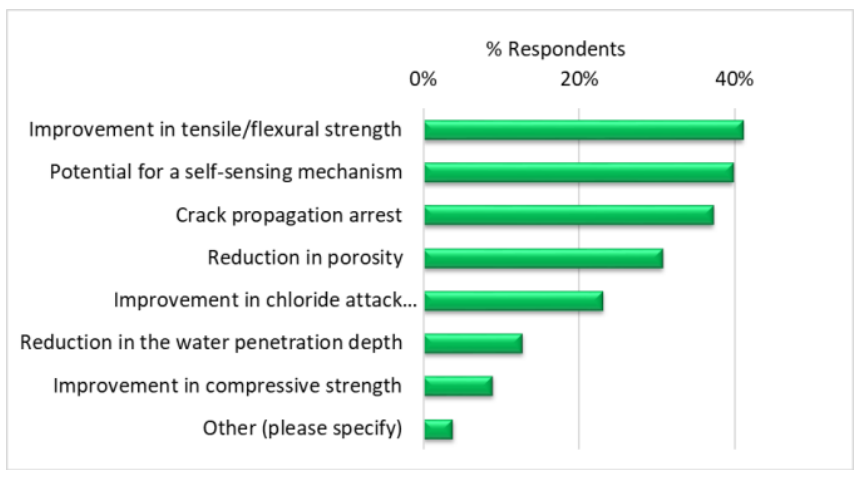

Finally, the main barriers to using graphene nanomaterials in construction are shown in Figure 9, with the potential upfront cost of the material being chosen by $61.5 \%$ of the participants as a key blocker. It was cited by a participant that "As I understand it, the cost of graphene is prohibitively expensive and the lack of availability for use on a commercial scale will inhibit growth." This is followed by lack of industry standards and guidance $(50 \%)$ and technical understanding (35.9\%). Only 1 of the 78 respondents mentioned Health, safety and environmental effects as a potential barrier to introducing this new material.

Figure 9: The main barriers to using a graphenereinforced cement composites in construction (according to participants, up to two choices allowed)

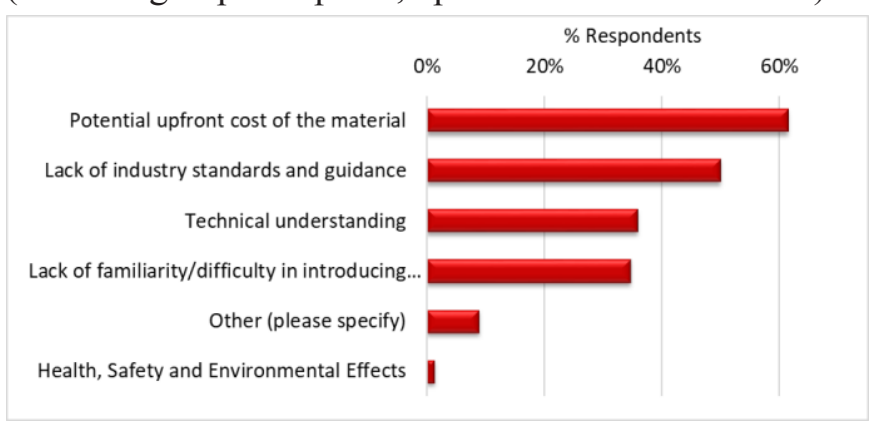

\section{Graphene market and commercial impact}

The high cost of graphene nanomaterials has been quoted in the survey as one of the key barriers for their use in concrete. Therefore, an overview of the graphene market and the commercial impact is presented in this section.

The material production method along with the quality of GNPs are closely related to the cost of the material (Novoselov et al., 2012). For example, as shown in Figure 10, graphene produced with mechanical exfoliation is of very high quality but the cost is also high, resulting in a material that would be most suitable for very niche applications in advanced electronics. The cost of such graphene would be prohibiting for construction applications. Instead, a cheaper and more widely available material can be produced with Liquid Phase Exfoliation, however, this method will produce a lower quality graphene. As an indication of cost differences, a graphene nanopowder which is only $1.6 \mathrm{~nm}$ thick (high quality) cost $300 \$$ for $1 \mathrm{~g}$ whilst if the quality reduces to a $60 \mathrm{~nm}$ thick graphene, the cost reduces by orders of magnitude to $250 \$$ for $100 \mathrm{~g}$ (Graphene Supermarket, 2018).

Figure 10: Simplified correlation between graphene nanomaterial quality and cost based on two production methods (adjusted from (Novoselov et al., 2012)

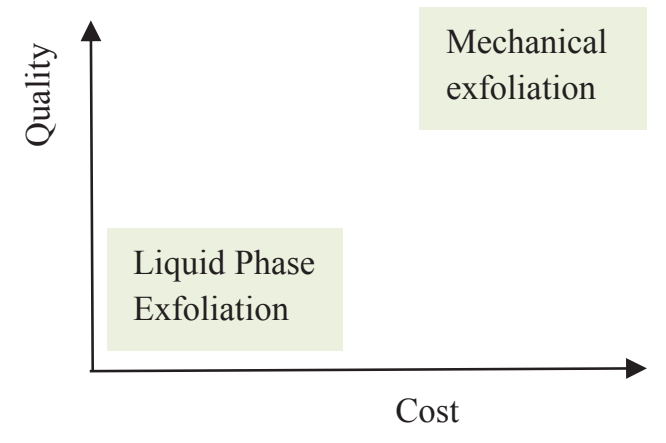


Undertaking a cost analysis can be challenging. Many commercial rates are confidential and the cost of graphene not only depends on the quality but also on the buying power of the organisation and technological advances in production methods. Mass production of graphene is not yet cost effective and very few companies dominate the market. A market research study by Technavio (2016) showed that the expected cost of graphene production will reduce significantly after 2020 (compared to 2016) and this will also increase the potential addressable market for graphene, hence reducing the costs further.

\section{Health, safety and sustainability}

Despite that Health, safety and environmental effects of graphene nanomaterials in construction were not identified as barriers by most survey participants, they are still important considerations for the successful introduction of this novel material. The latest guidance on health and safety is presented here, along with the results of a lifecycle assessment for introducing graphene in concrete.

\subsection{Health and safety $(H \& S)$}

Under current legislation it is not mandatory to declare the presence of nanomaterials in commercial products hence it is very challenging to identify accurate information about such use of nanomaterials and their properties (Jones et al., 2016). Nanomaterials could persist in the environment for a long time and they could also be absorbed through the skin or through ingestion (Di Sia, 2017). In the UK, the Health and Safety Executive (HSE) (2013) has published guidance around the use of high aspect ratio nanomaterials (HARNs) at work that details the control measures required when handling nanoparticles. Recently, IOSH (2017), in collaboration with Loughborough University, have undertaken a thorough study on nanotechnology in construction and produced a thorough report of what we know and what we don't (Gibb et al., no date). The key findings are as follows:

- $\quad$ The shape of the material plays an important role in its bio persistence and toxicity. Fibres that are narrower than $1 \mu \mathrm{m}$ and longer than 5-10 $\mu \mathrm{m}$ cannot be easily removed from the lungs via the usual protective mechanisms of our bodies. Long, straight carbon nanotubes (CNTs) are considered harmful and more problematic.

- Nanomaterials are not considered hazardous if they are bound in a solid, stable structure (eg. in concrete) and the risk would only arise if the workers are exposed to nanomaterials in the form of dust or aerosols (eg. when cutting or demolishing structures).

- $\quad$ Significantly more research is needed around Health and Safety $(H \& S)$ of nanomaterials. When such materials are knowingly used, it should be accurately recorded (eg. in the CDM Health and Safety file).

- Dust is a very significant, existing hazard during construction and demolition and the use of nanomaterials in products is unlikely to add significantly to the presents risks. Therefore, robust management of existing risks must be a key priority.

- Nanomaterials can be made "safe by design"; for example by reducing the length of carbon nanotubes (CNTs) or improving their stability within matrices. The risk and benefits must also be balanced at design stage. For example, a nano-enabled self-cleaning window will reduce the need for work at height.

- All available information (such as type and location of nanomaterials) should be accurately recorded in order to allow for a better management of risks and future generations to respond suitably.

In summary, nanomaterials might account for up to half of the building materials by 2025 (iosh, 2017) but our understanding around the H\&S aspects is still very limited. The HSE and IOSH in the UK, currently recommend a precautionary approach and place the focus on the robust management of existing risk. Further research in the toxicity and biopersistence of nanoparticles is needed for the industry to correctly mitigate all risks (ACI Committee 241, 2017).

\subsection{Sustainability}

Similarly to the H\&S effect of nanomaterials, their effects on the environment are not well understood by the scientific community and industry. Graphene is described as a nonbiodegradable material (Arvidsson, Molander and Sandén, 2013) which could have implications for its end of life disposal or re-use. A cradle-to-grave lifecycle assessment (LCA) has been undertaken to compare two graphene production methods - ultrasonication and chemical reduction (Arvidsson, Kushnir, Sanden, \& Molander, 2014). However, a full LCA of using GNPs in concrete has not been undertaken to date. A cradle-togate LCA (Arena and Papanikolaou, 2018) shows that the production of $1 \mathrm{~kg}$ of G2NanPaste (GNPs product) corresponds to $0.17 \mathrm{~kg}_{\mathrm{CO} 2}$ equivalent (the production of $1 \mathrm{~kg}$ of Portland Cement, CEM I, corresponds to $0.86 \mathrm{~kg}_{\mathrm{CO} 2}$ equivalent (SimaPro, 2015)), meaning that GNPs could be environmentally friendly if used as a supplement for some of the cement. These are preliminary results only however, they indicate that the contribution of GNPs to the carbon footprint is limited and moreover GNPs could help to improve concrete performance without increasing the dosage of cement. More importantly, GNPs provide an opportunity to generate new properties in concrete (such as self-sensing), hence allowing for a proactive response to deterioration that in turns saves time and money.

\section{Conclusion}

The use of graphene nanomaterials in concrete is an emerging area of research and has gathered great momentum since graphene's isolation in 2004. GNPs have been found to improve the concrete performance and they also have the potential to create advanced functionalities such as a selfsensing mechanism. An industry survey indicated that the tensile/flexural strength improvement and the self-sensing 
functionalities are the greatest opportunities for graphene in concrete. The high cost of the material has been cited as the main barrier followed by the lack of industry standards. The cost of graphene depends primarily on the quality, so a compromise can be found between cost and quality for construction applications. Finally, health, safety and sustainability aspects are not well understood and significantly more research is needed in these areas to ensure that graphene nanomaterials can be safely used without impacting the environment.

\section{Acknowledgements}

The authors would like to thank the Engineering and Physical Sciences Research Council (EPSRC CDT Grant No. $\mathrm{EP} / \mathrm{L} 016095 / 1)$ and Costain Group for funding this research as well as BASF and Nanesa for providing materials and technical advice.

\section{References}

ACI Committee 241 (2017) 241R-17: Report on Application of Nanotechnology and Nanomaterials in Concrete. American Concrete Institute.

Al-Dahawi, A. et al. (2017) 'Assessment of self-sensing capability of Engineered Cementitious Composites within the elastic and plastic ranges of cyclic flexural loading', Construction and Building Materials, 145, pp. 1-10. doi: 10.1016/j.conbuildmat.2017.03.236.

Al-Tabbaa, A. et al. (2017) 'Smart biomimetic construction materials for next generation infrastructure', in International Symposium for Next Generation Infrastructure, pp. 28-37.

Al-Tabbaa, A. and Paine, K. (2018) 'Biomimetic cementitious construction materials for next-generation infrastructure', pp. 1-10.

Alkhamis, M. and Imqam, A. (2018) 'New Cement Formulations Utilizing Graphene Nano Platelets to Improve Cement Properties and Long-term Reliability in Oil Wells', SPE-192342-MS.

Arena, N. and Papanikolaou, I. (2018) GNPs in concrete Lifecycle Assessment LCA.

Arvidsson, R., Molander, S. and Sandén, B. A. (2013) 'Review of Potential Environmental and Health Risks of the Nanomaterial Graphene', Human and Ecological Risk Assessment: An International Journal, (January 2012), p. 130313080735004. doi: 10.1080/10807039.2012.702039.

Bai, S. et al. (2018) 'Enhancement of mechanical and electrical properties of graphene/cement composite due to improved dispersion of graphene by addition of silica fume', Construction and Building Materials. Elsevier Ltd, 164, pp. 433-441. doi: 10.1016/j.conbuildmat.2017.12.176.

Bai, S. et al. (2018) 'Research on electrical conductivity of graphene / cement composites'.

Bennetts, J. et al. (2016) 'Bridge data - what do we collect and how do we use it?', pp. 531-536. doi:

10.1680/tfitsi.61279.531.

Chen, P. W. and Chung, D. D. L. (1996) 'Concrete as a new strain stress sensor', Composites Part B-Engineering, 27(1), pp. 11-23. doi: 10.1016/1359-8368(95)00002-x.

Chuah, S. et al. (2014) 'Nano reinforced cement and concrete composites and new perspective from graphene oxide', Construction and Building Materials. Elsevier Ltd, 73, pp. 113-124. doi: 10.1016/j.conbuildmat.2014.09.040.

Chung, D. D. L. (1998) 'Self-monitoring structural materials', 22.

Chung, D. D. L. (2002) 'Piezoresistive Cement-Based Materials for Strain Sensing', Journal of Intelligent Material Systems and Structures, 13(9), pp. 599-609. doi: 10.1106/104538902031861.

Chung, D. D. L. (2012) 'Carbon materials for structural selfsensing, electromagnetic shielding and thermal interfacing', Carbon. Elsevier Ltd, 50(9), pp. 3342-3353. doi: 10.1016/j.carbon.2012.01.031.

Dai, Y. et al. (2010) 'Electromagnetic wave absorbing characteristics of carbon black cement-based composites', Cement and Concrete Composites. Elsevier Ltd, 32(7), pp. 508-513. doi: 10.1016/j.cemconcomp.2010.03.009.

Dimov, D. et al. (2018) 'Ultrahigh Performance Nanoengineered Graphene-Concrete Composites for Multifunctional Applications', Advanced Functional Materials. Wiley-Blackwell, 28(23), p. 1705183. doi: 10.1002/adfm.201705183.

Du, H., Gao, H. J. and Pang, S. D. (2016) 'Improvement in concrete resistance against water and chloride ingress by adding graphene nanoplatelet', Cement and Concrete Research. Elsevier Ltd, 83, pp. 114-123. doi:

10.1016/j.cemconres.2016.02.005.

Du, H. and Pang, S. D. (2015) 'Enhancement of barrier properties of cement mortar with graphene nanoplatelet', Cement and Concrete Research. Elsevier Ltd, 76, pp. 10-19. doi: 10.1016/j.cemconres.2015.05.007.

Gardner, D. et al. (2018) 'A survey on problems encountered in current concrete construction and the potential benefits of self-healing cementitious materials', Case Studies in Construction Materials, 8(October 2017), pp. 238-247. doi: 10.1016/j.cscm.2018.02.002.

Geim, A. K. and Novoselov, K. S. (2007) 'The rise of graphene', Nature Materials, 6(3), pp. 183-191. doi: 10.1038/nmat1849.

Gibb, A. et al. (no date) 'Nanotechnology in construction and demolition - what we know, what we don't. Report for the Institution of Occupational Safety and Health'.

Graphene Supermarket (2018). Available at:

https://graphene-supermarket.com/Grade-AO-1-1.6-nm/ (Accessed: 1 December 2018).

Han, B. et al. (2017) 'Enhancing mechanisms of multi-layer graphenes to cementitious composites', Composites Part A: Applied Science and Manufacturing. Elsevier Ltd, 101, pp. 143-150. doi: 10.1016/j.compositesa.2017.06.016.

Han, B., Ding, S. and Yu, X. (2015) 'Intrinsic self-sensing concrete and structures: A review', Measurement: Journal of the International Measurement Confederation. Elsevier Ltd, 
59, pp. 110-128. doi: 10.1016/j.measurement.2014.09.048 Han, B., Yu, X. and Ou, J. (2014) Self-sensing concrete in smart structures. Oxford: Elsevier Inc.

Health and Safety Executive (HSE) (2013) 'Using

nanomaterials at work'. Crown copyright, pp. 1-27.

HM Infrastructure and Projects Authority (2016) National Infrastructure Delivery Plan 2016-2021. Available at: https://www.gov.uk/government/publications/nationalinfrastructure-delivery-plan-2016-to-2021.

HM Treasury (2010) Infrastructure Cost Review: Main Report, Group. Available at: http://www.hmtreasury.gov.uk/d/cost_review_main211210.pdf.

Horszczaruk, E., Sikora, P. and Lukowski, P. (2016) 'Application of Nanomaterials in Production of Self-Sensing Concretes: Contemporary Developments and Prospects', Archives of Civil Engineering, 62(3), pp. 61-74. doi: 10.1515/ace-2015-0083.

iosh (2017) Nanotechnology in construction and demolition. Wigston, Leicestershire, UK. Available at: www.iosh.co.uk/nanotechnology.

Jones, W. et al. (2016) 'Nanomaterials in construction - what is being used, and where?', Proceedings of the Institution of Civil Engineers - Construction Materials, pp. 1-14. doi: 10.1680/jcoma.16.00011.

Liu, Q. et al. (2016) 'Experimental investigation on mechanical and piezoresistive properties of cementitious materials containing graphene and graphene oxide nanoplatelets', Construction and Building Materials. Elsevier Ltd, 127, pp. 565-576. doi: 10.1016/j.conbuildmat.2016.10.024.

Lu, Z. et al. (2017) 'Steric stabilization of graphene oxide in alkaline cementitious solutions: Mechanical enhancement of cement composite', Materials and Design. Elsevier, 127(April), pp. 154-161. doi: 10.1016/j.matdes.2017.04.083. Madhuri, S. and Maheshwar, S. (2015) 'Structure and properties of graphene', in Graphene: An Introduction to the Fundamentals and Industrial Applications. Beverly,: Scrivener Publishing LLC and John Wiley \& Sons, Inc.

Neville, A. . (2011) Properties of concrete. 5th edn. Pearson Education Limited.

Norhasri, M. S. M., Hamidah, M. S. and Fadzil, A. M. (2017) 'Applications of using nano material in concrete: A review', Construction and Building Materials. Elsevier Ltd, 133, pp. 91-97. doi: 10.1016/j.conbuildmat.2016.12.005.

Novoselov, K. S. et al. (2012) 'A roadmap for graphene', Nature. Nature Publishing Group, 490(7419), pp. 192-200. doi: 10.1038/nature11458.

Pang, S. D. et al. (2014) 'Strain and damage self-sensing cement composites with conductive graphene nanoplatelet', 9061, p. 906126. doi: 10.1117/12.2045329.

Papanikolaou, I. (2017) Graphene / cement composites for sprayed concrete linings in underground construction Graphene / cement composites for sprayed concrete linings in underground construction Author: Ioanna Papanikolaou. University of Cambridge.
Papanikolaou, I., Litina, C. and Al-tabbaa, A. (2018) 'A preliminary study into the effect of superplasticisers on the dispersion of graphene materials in cement', in 12th fib International PhD Symposium in Civil Engineering. Czech Technical University in Prague, Prague, Czech Republic, pp. 123-130.

Paul, S. C. et al. (2018) 'Properties of cement-based composites using nanoparticles: A comprehensive review', Construction and Building Materials. Elsevier Ltd, 189, pp. 1019-1034. doi: 10.1016/j.conbuildmat.2018.09.062.

Rehman, S. K. U. et al. (2017) 'A sustainable graphene based cement composite', Sustainability (Switzerland), 9(7), pp. 120. doi: 10.3390/su9071229.

Shamsaei, E. et al. (2018) 'Graphene-based nanosheets for stronger and more durable concrete: A review', Construction and Building Materials. Elsevier Ltd, 183, pp. 642-660. doi: 10.1016/j.conbuildmat.2018.06.201.

Di Sia, P. (2017) 'Nanotechnology Among Innovation, Health and Risks', Procedia - Social and Behavioral Sciences. The Author(s), 237(June 2016), pp. 1076-1080. doi: 10.1016/j.sbspro.2017.02.158.

SimaPro (2015) 'LCA, 8.3. Release date: 2015-05-29. Available at: http://www.simapro.co.uk'. Available at: http://www.simapro.co.uk.

Sobolkina, A. et al. (2012) 'Dispersion of carbon nanotubes and its influence on the mechanical properties of the cement matrix', Cement and Concrete Composites. Elsevier Ltd, 34(10), pp. 1104-1113. doi:

10.1016/j.cemconcomp.2012.07.008.

Spencer, B. F. (2009) Structural Health Monitoring of Civil Infrastructure: from Research to Engineering Practice. Cambridge.

Sun, S. et al. (2017) 'Multi-layer graphene-engineered cementitious composites with multifunctionality/intelligence', Composites Part B: Engineering. Elsevier Ltd, 129, pp. 221232. doi: 10.1016/j.compositesb.2017.07.063.

Technavio (2016) Global graphene market 2016-2020.

Van Tittelboom, K. and De Belie, N. (2013) Self-healing in cementitious materials-a review, Materials. doi: 10.3390/ma6062182.

Tong, T. et al. (2016) 'Investigation of the effects of graphene and graphene oxide nanoplatelets on the micro- and macroproperties of cementitious materials', Construction and Building Materials. Elsevier Ltd, 106, pp. 102-114. doi: 10.1016/j.conbuildmat.2015.12.092.

Wang, B., Jiang, R. and Wu, Z. (2016) 'Investigation of the Mechanical Properties and Microstructure of Graphene Nanoplatelet-Cement Composite'. doi: 10.3390/nano6110200.

Wang, B. and Zhao, R. (2017) 'Effect of graphene nanosheets on the chloride penetration and microstructure of the cement based composite', Construction and Building Materials. Elsevier Ltd, 161, pp. 715-722. doi: 10.1016/j.conbuildmat.2017.12.094.

Wang, B., Zhao, R. and Zhang, T. (2018) 'Pore structure and 
durability of cement-based composites doped with graphene nanoplatelets', Materials Express, 8(2), pp. 149-156. doi: 10.1166/mex.2018.1421.

$\mathrm{Xu}, \mathrm{Y}$. (2012) 'Health Monitoring of Large Civil Structures', in The Second Future Infrastructure Forum (FIF2).

Cambridge, pp. 17-18.

$\mathrm{Xu}, \mathrm{Y}$. et al. (2018) 'A holistic review of cement composites reinforced with graphene oxide', Construction and Building Materials, 171, pp. 291-302. doi:

10.1016/j.conbuildmat.2018.03.147.

Zhao, L. et al. (2018) 'Investigation of dispersion behavior of GO modified by different water reducing agents in cement pore solution', Carbon. Elsevier Ltd, 127, pp. 255-269. doi: 10.1016/j.carbon.2017.11.016.

Zheng, Q. et al. (2017) 'Graphene-engineered cementitious composites: Small makes a big impact', Nanomaterials and Nanotechnology, 7, pp. 1-18. doi: 10.1177/1847980417742304.

Zhu, W., Bartos, M. and Porro, A. (2004) 'Application of nanotechnology in construction', Materials and Structures/Materiaux et Constructions, 37(November), pp. 649-658 